Supporting Information

\title{
A Three-in-one Functional Silica Nanocarrier with Singlet Oxygen Generating, Storage/release and Self-monitoring for Enhanced Fractional Photodynamic Therapy
}

Long Jiao, ${ }^{1}$ Xiaoye Zhang, ${ }^{2}$ Jingnan Cui, ${ }^{1}$ Xiaojun Peng, ${ }^{1}$ Fengling Song 1,3, *

${ }^{1}$ State Key Laboratory of Fine Chemicals, Dalian University of Technology, No. 2 Linggong Road, High-tech District, Dalian, 116024, P. R. China

2 Marine Engineering College, Dalian Maritime University, No. 1 Linghai Road, High-tech District, Dalian, 116026, P. R. China

${ }^{3}$ Institute of Molecular Sciences and Engineering, Shandong University, Qingdao 266237, P. R. China

*Corresponding author: songfl@dlut.edu.cn; songfl@,sdu.edu.cn Phone/Fax: +86-411-84986307 


\section{Table of content}

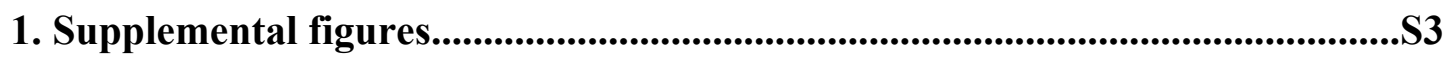

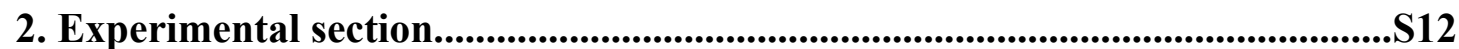

3. Supplemental spectra............................................................................................S23

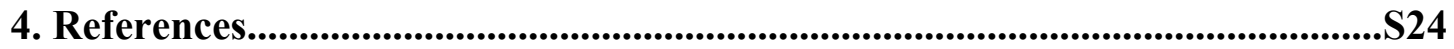




\section{Supplemental figures}

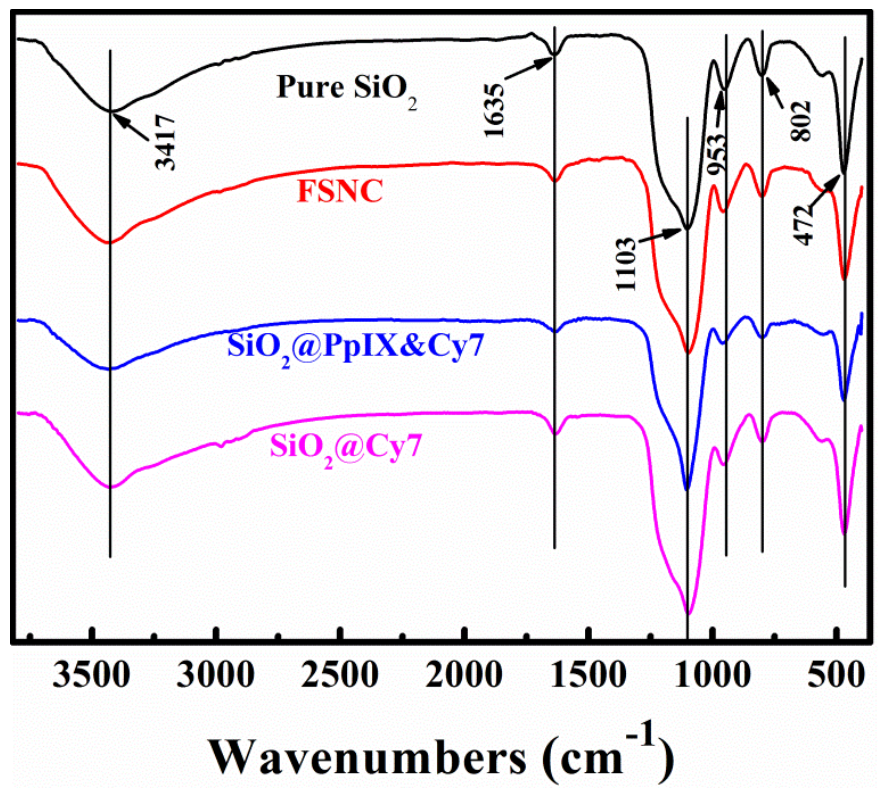

Figure S1. FTIR of FSNC, SiO $@$ @PIX\&Cy7 and $\mathrm{SiO}_{2} @ \mathbf{C y} 7$. 

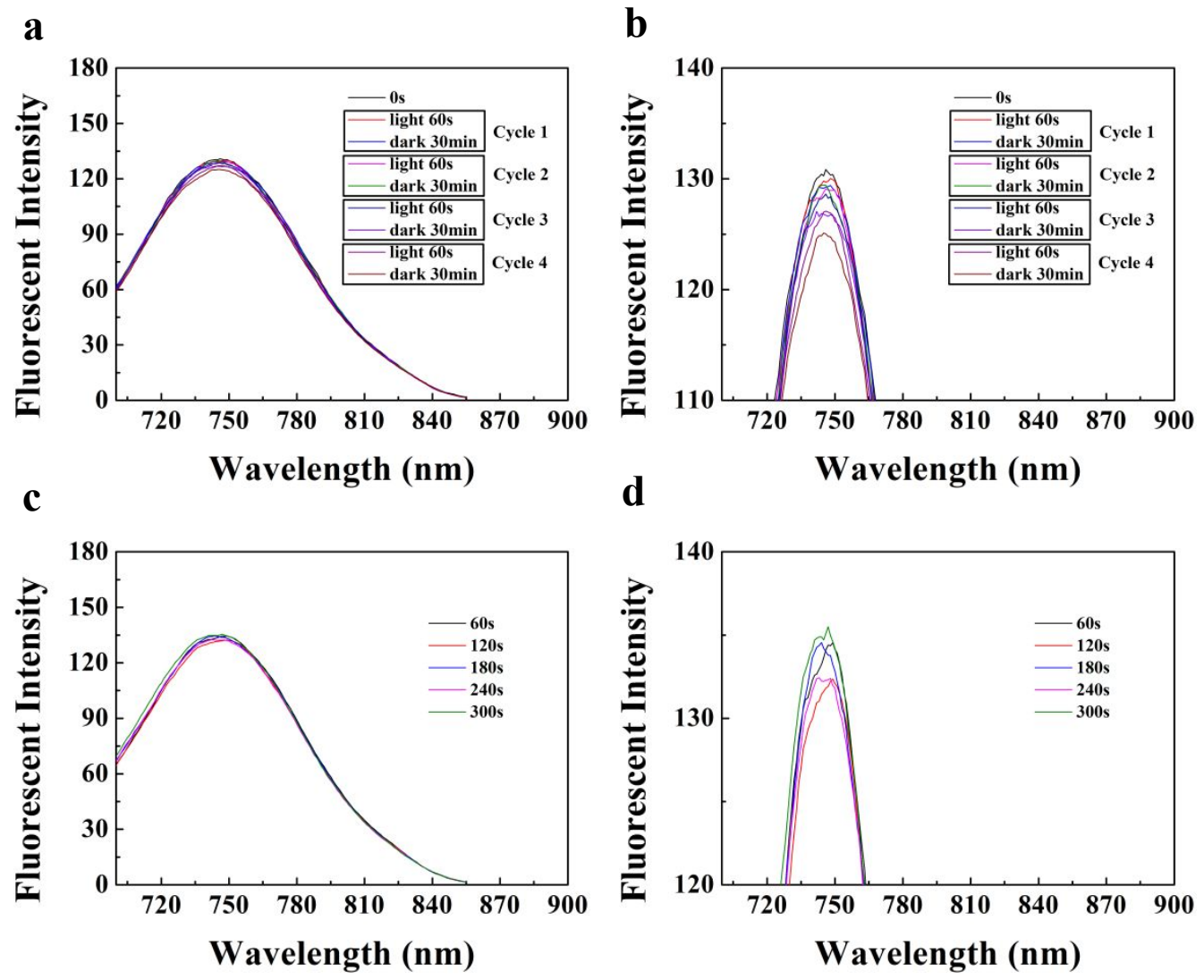

Figure S2. (a) ${ }^{1} \mathrm{O}_{2}$ generation of $\mathbf{S i O}_{2} @ \mathbf{C y} 7$ by fluorescence spectra in absolute ethanol (Partical enlarged detail was shown in Figure S2(b) ); (c) Photostability evalution of $\mathbf{S i O}_{2} @ \mathbf{C y 7}$ (Partical enlarged detail was shown in Figure S2(d)). $C_{\mathrm{SiO} 2 @ \mathrm{Cy} 7}=0.5 \mathrm{mg} \mathrm{mL}^{-1} ; \lambda_{\mathrm{ex}}=635 \mathrm{~nm} ; \mathrm{LED}$ array: $\lambda_{\mathrm{ex}}=660 \mathrm{~nm}, 25 \mathrm{~mW} / \mathrm{cm}^{2}$. 


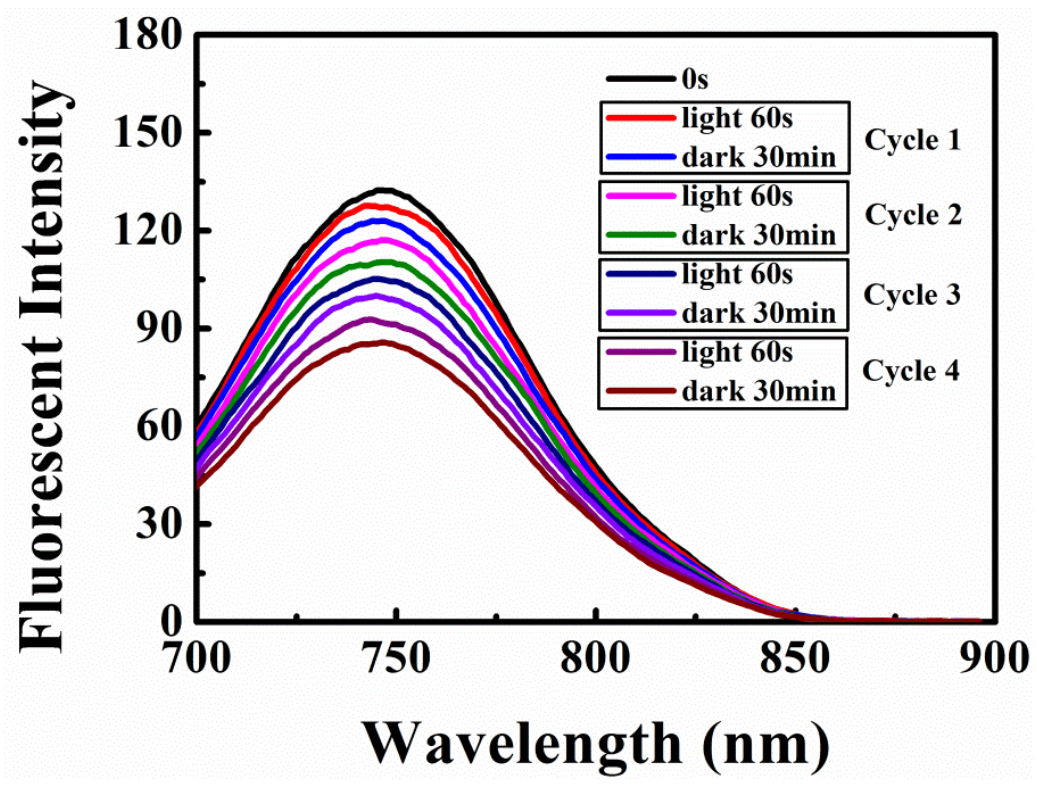

Figure S3. Release stability of ${ }^{1} \mathrm{O}_{2}$ of FSNC. ${ }^{1} \mathrm{O}_{2}$ generation of FSNC was measured by fluorescence spectra after FSNC was stored in absolute ethanol for $14 \mathrm{~d}\left(C_{\mathrm{FSNC}}=\right.$ $0.5 \mathrm{mg} \mathrm{mL}^{-1} ; \lambda_{\mathrm{ex}}=635 \mathrm{~nm}$; LED array: $\lambda_{\mathrm{ex}}=660 \mathrm{~nm}, 25 \mathrm{~mW} / \mathrm{cm}^{2}$. 
a

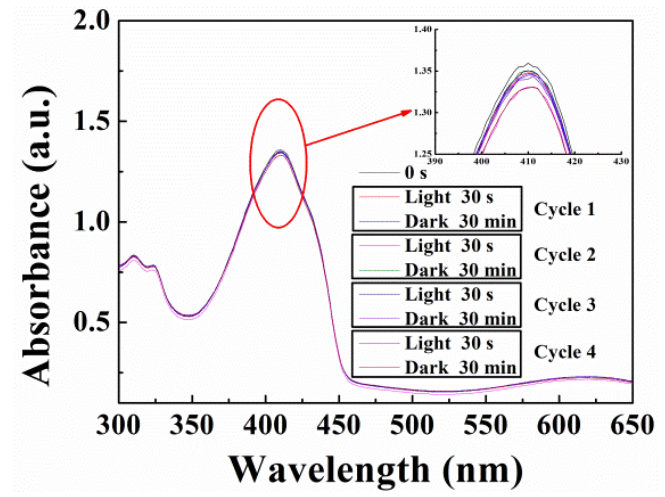

b

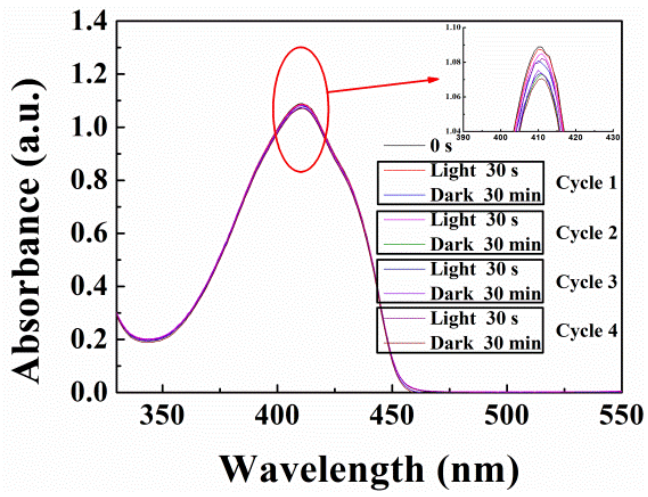

Figure S4. Detection of ${ }^{1} \mathrm{O}_{2}$ generation by disappearance of absorbance of DPBF at $410 \mathrm{~nm}$ in absolute ethanol containing separately $\mathbf{S i O}_{\mathbf{2}} @ \mathbf{C y} 7\left(0.1 \mathrm{mg} \mathrm{mL}^{-1}\right)$ (a) and DPBF $(50 \mu \mathrm{M})(\mathrm{b})$ after light irradiation $\left(660 \mathrm{~nm}, 25 \mathrm{~mW} / \mathrm{cm}^{2}\right)$ for different times (One black square represents one cycle: Light for 30s and then drak for $30 \mathrm{~min}$ ). 


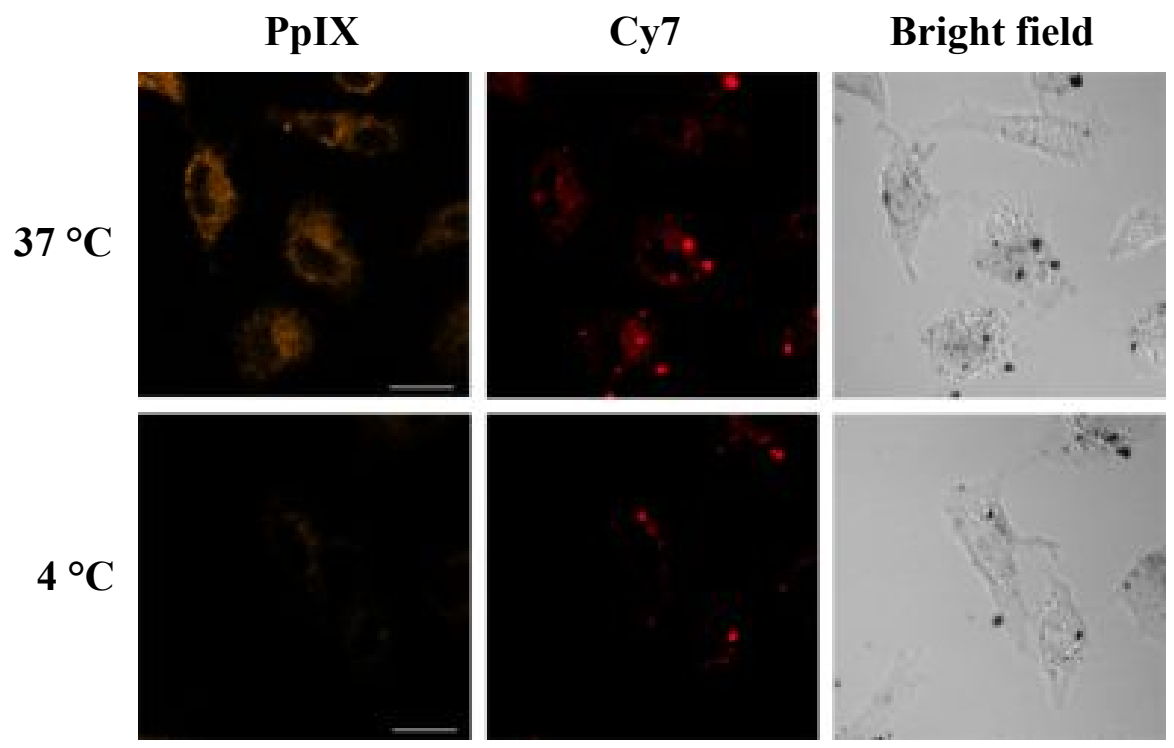

Figure S5. Cellular uptake of FSNC in HeLa cells. HeLa cells were co-incubated with FSNC ( $\left.2 \mu \mathrm{g} \mathrm{mL}^{-1}\right)$ at $37{ }^{\circ} \mathrm{C}$ (a) and $4{ }^{\circ} \mathrm{C}$ for $4 \mathrm{~h}$, respectively. Orange channel (PpIX): $\lambda_{\mathrm{ex}}=405 \mathrm{~nm}, \lambda_{\mathrm{em}}=610-630 \mathrm{~nm}$; red channel (Cy7): $\lambda_{\mathrm{ex}}=635 \mathrm{~nm}, \lambda_{\mathrm{em}}=$ $655-755 \mathrm{~nm}$. Scale bar $=20 \mu \mathrm{m}$. 

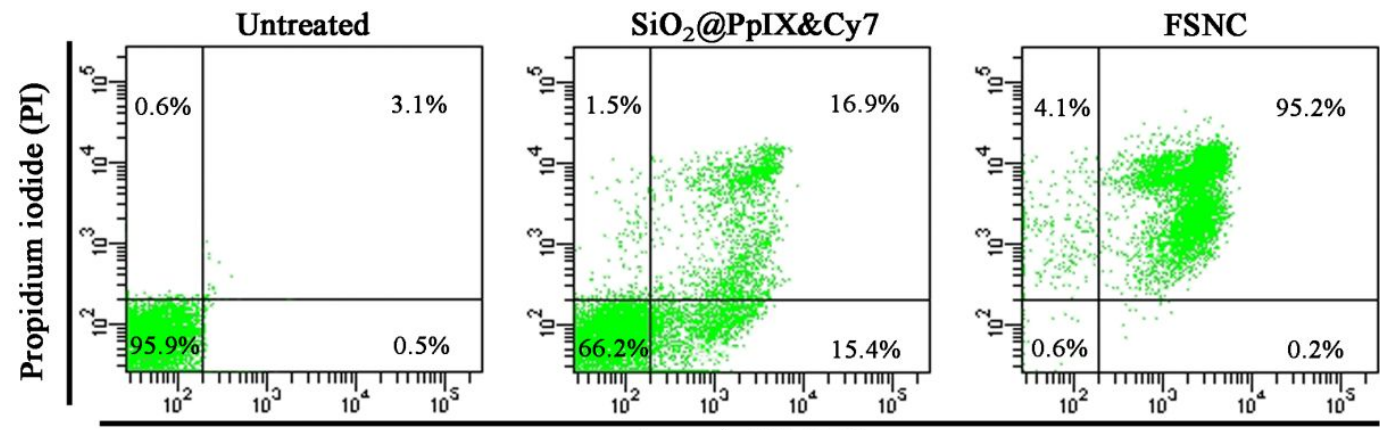

Annexin V-FITC

Figure S6. Apoptosis in HeLa cells detected by fluorescence activated cell sorting (FACS). HeLa cells treated with FSNC or $\mathrm{SiO}_{2} @ \mathrm{PpIX} \& \mathrm{Cy} 7$ were irradiated by the red LED array at a power density of $25 \mathrm{~mW} / \mathrm{cm}^{2}\left(\lambda_{\mathrm{ex}}=660 \mathrm{~nm}\right)$ for $2 \mathrm{~min}$ and then kept under dark for $30 \mathrm{~min}$. Percentages of live (PI-/Annexin V-), early apoptotic $(\mathrm{PI}-/$ Annexin $\mathrm{V}+$ ), late apoptotic $(\mathrm{PI}+/$ Annexin $\mathrm{V}+$ ) and necrotic $(\mathrm{PI}+/$ Annexin $\mathrm{V}-)$ cells were indicated in each quadrant. 


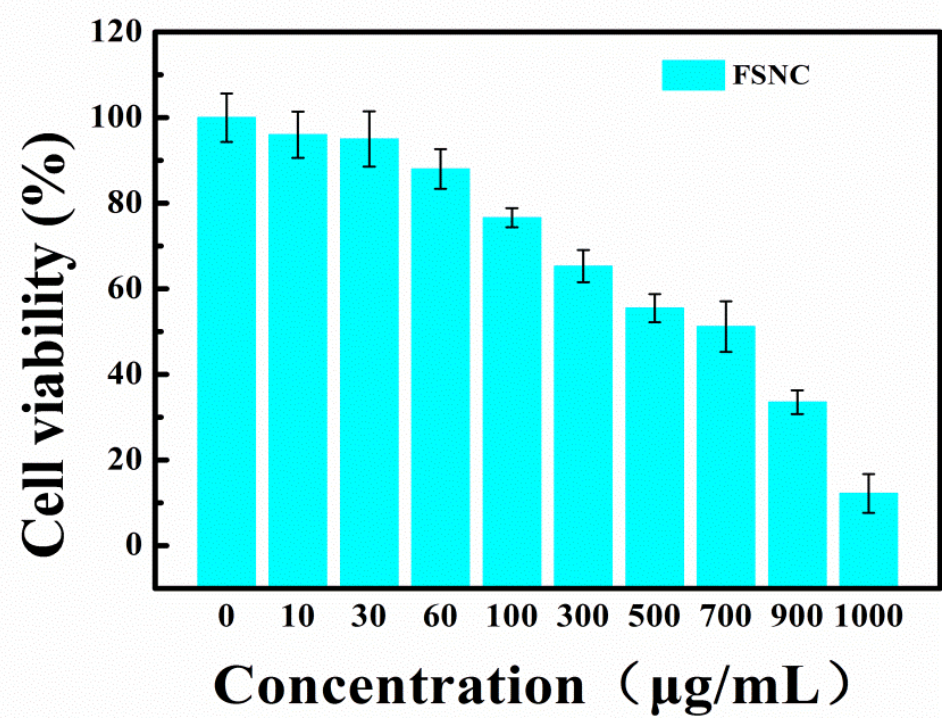

Figure S7. Dark cytotoxicity evaluation of FSNC on HeLa cells. Data are presented as the mean value $\pm \operatorname{SD}(n=6)$. 

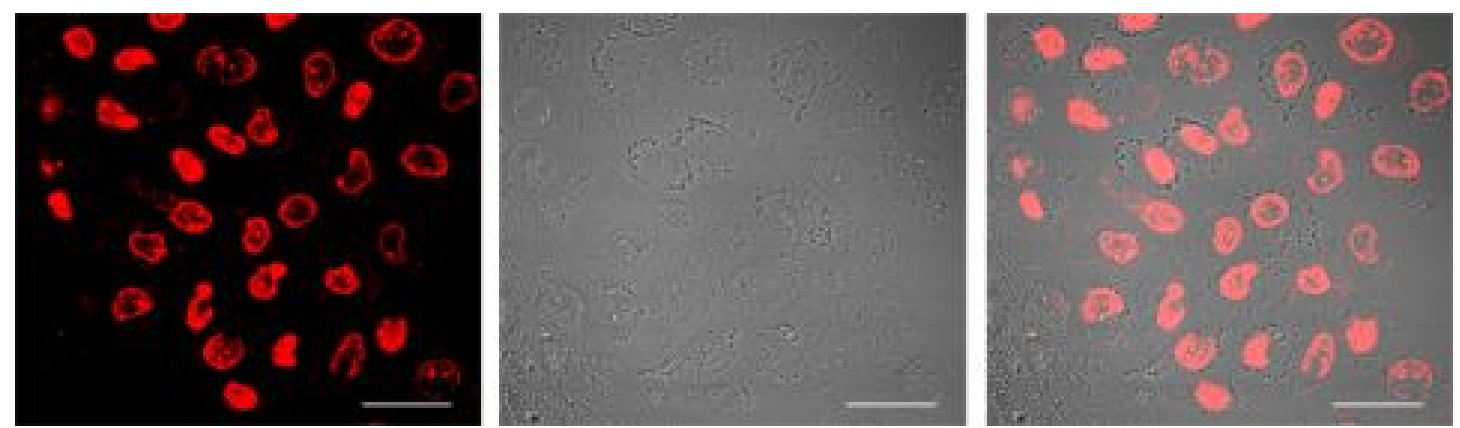

Figure S8. Morphology Change of HeLa Cells via Propidium Iodide (PI) single staining method after PDT (Light irradiation for $2 \mathrm{~min}$, and then dark for $4 \mathrm{~h}$ ). HeLa cells were incubated with FSNC at $2 \mu \mathrm{g} \mathrm{mL}^{-1}$ under light irradiation $\left(\lambda_{\mathrm{ex}}=660 \mathrm{~nm}, 25\right.$ $\mathrm{mW} / \mathrm{cm}^{2}$ ) for $2 \mathrm{~min}$, then under dark for $4 \mathrm{~h} ; \lambda_{\mathrm{ex}}=515 \mathrm{~nm}, \lambda_{\mathrm{em}}=570-590 \mathrm{~nm}$; Scale bar $=40 \mu \mathrm{m}$. 


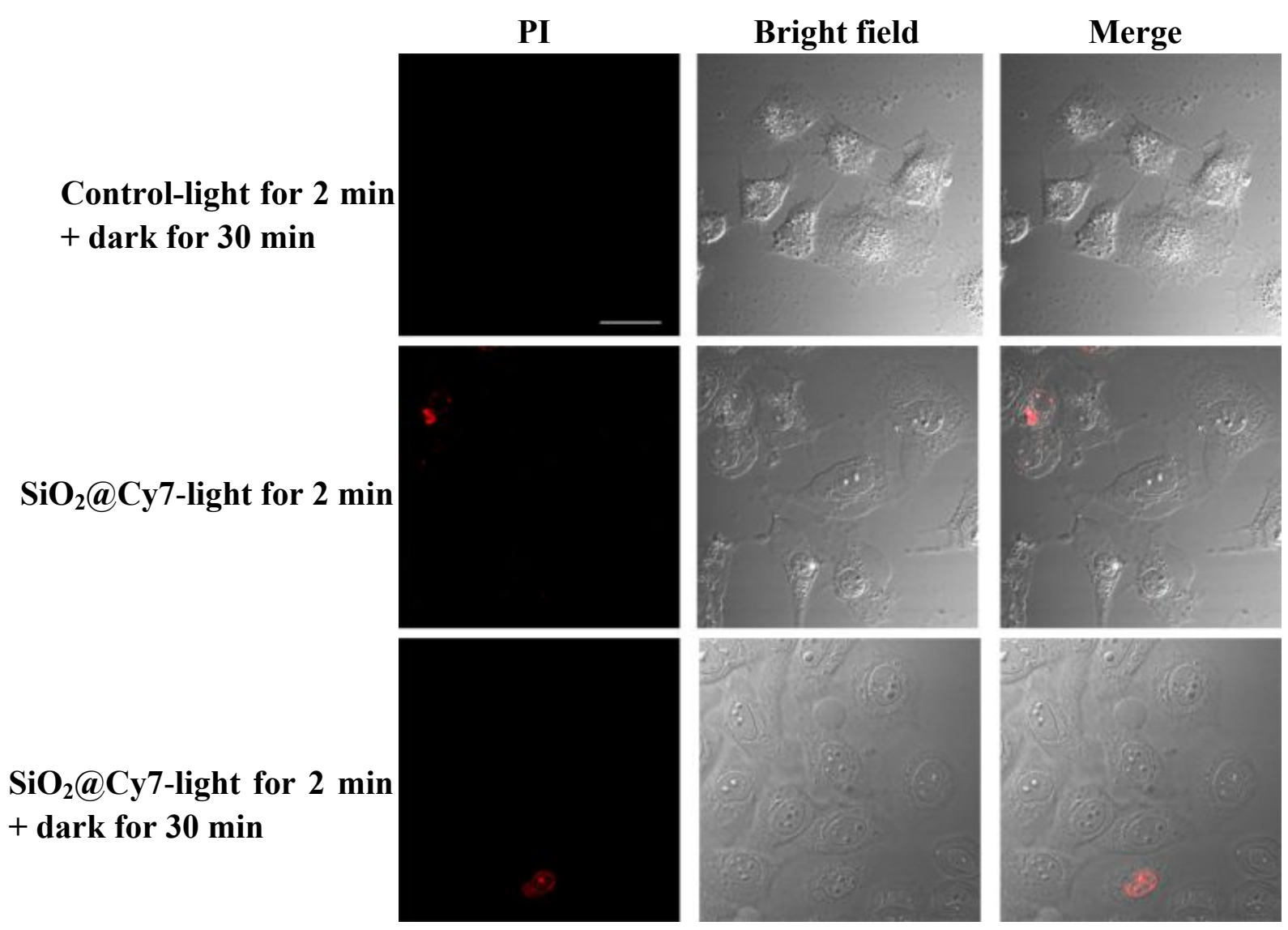

Figure S9. Morphology Change of HeLa Cells via Propidium Iodide (PI) single staining method. HeLa cells were respectively incubated with $\mathbf{S i O}_{2} @ \mathbf{C y} 7$ at $2 \mu \mathrm{g}$ $\mathrm{mL}^{-1}$ under light irradiation $\left(\lambda_{\mathrm{ex}}=660 \mathrm{~nm}, 25 \mathrm{~mW} / \mathrm{cm}^{2}\right)$ for $2 \mathrm{~min}$, then under dark for $30 \mathrm{~min} ; \lambda_{\mathrm{ex}}=515 \mathrm{~nm}, \lambda_{\mathrm{em}}=570-590 \mathrm{~nm}$; Scale bar $=30 \mu \mathrm{m}$. 


\section{Experimental section}

\subsection{Materials}

All reactions were carried out under a nitrogen atmosphere with dry, freshly distilled solvents under anhydrous conditions, unless otherwise noted. N,N-Dimethylformamide (DMF) was distilled from calcium hydride. PBS buffer ( $\mathrm{pH}$ $=7.4,10 \mathrm{mM}$ ) was prepared in our laboratory. Tetraethylorthosilicate (TEOS), (3-aminopropyl)triethoxysilane (APTES), (3-chloroproryl)trimethoxysilane (CPTES), 2-pyridone, cyclohexane, n-octanol, Triton X-100, acetone, absolute ethanol, acetonitrile and diethylether were high-purity products purchased from Sigma-Aldrich and used as received. Ultrapure deionized water from a Milli-Q ultrapure system was used for all the synthesis, purification, solution preparation and storage steps.

\subsection{Methods}

Mass spectrometric data were obtained on a LTQ Orbitrap XL mass spectrometer (Thermo Scientific). The crude product of $\mathrm{Cy} 7$ was purified by FLEXA Purification System from Agela Technologies using methanol and deionized water as mobile phase. The size and shape of the silica nanoparticles were characterized using a transmission electron microscope, TEM (Tecnai F30). Diameter measurements of nanoparticles were carried out at $25^{\circ} \mathrm{C}$ using a Nanozs 90 instrument (Malvern). FTIR measurements were performed on a 6700 FTIR spectrometer (Thermo Fisher). Confocal Fluorescence images were performed on a confocal laser scanning microscope (Fluoview FV1000, Olympus). MTT assays were measured on Microplate reader named Multiskan FC from Thermo scientific (Filter: $490 \mathrm{~nm}$ ). Fluorescence 
activated Cell Sorting (FACS) of HeLa cells were analyzed on BD FACSCanto flow cytometer.

\subsection{Preparation of FSNC, $\mathrm{SiO}_{2} @ \mathrm{PpIX \& Cy7}$ and $\mathrm{SiO}_{2} @ \mathrm{Cy} 7$}

To obtain sufficient stored ${ }^{1} \mathrm{O}_{2}$, the material mass of ${ }^{1} \mathrm{O}_{2}$ storage/release unit is 50-fold larger than that of the other two functional units. Thus the molar feeding ratio of each functional unit (PpIX : 2-pyridone : Cy7) in FSNC is $0.01 \mathrm{mmol}: 0.50 \mathrm{mmol}$ : $0.01 \mathrm{mmol}$. The synthesis routes are shown in experimental section of supporting information. The MS spectra of derivatives are given in supporting information (Figure S10 and S11).
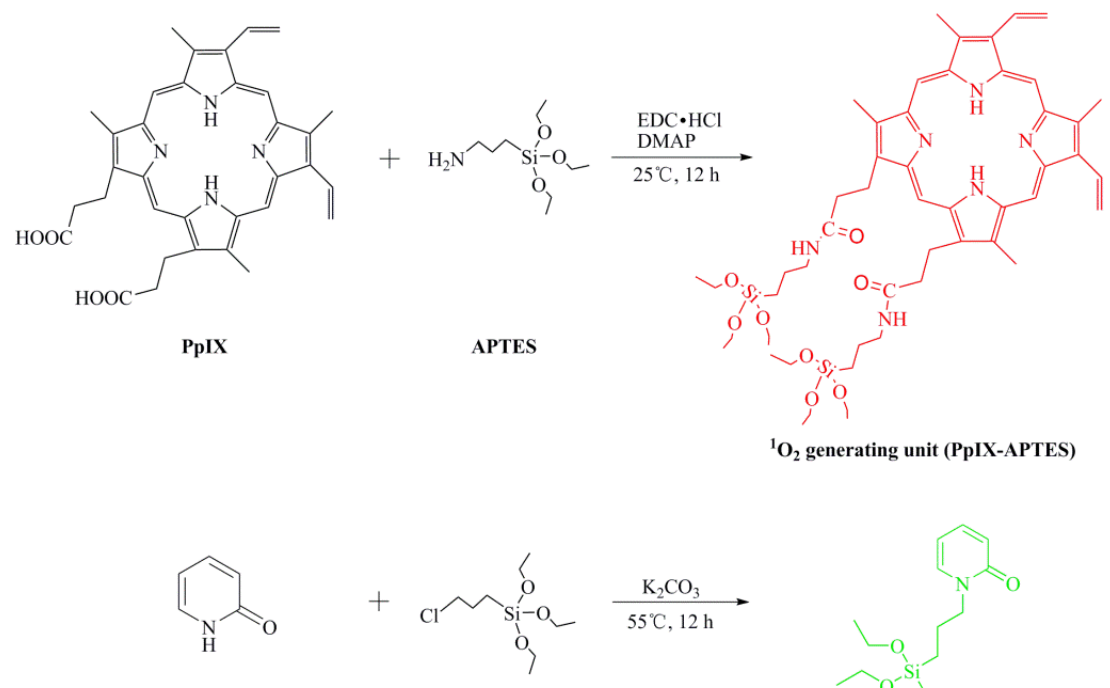

2-pyridone

CPTES

${ }^{1} \mathrm{O}_{2}$ storage/release unit (2-pyridone-CPTES)
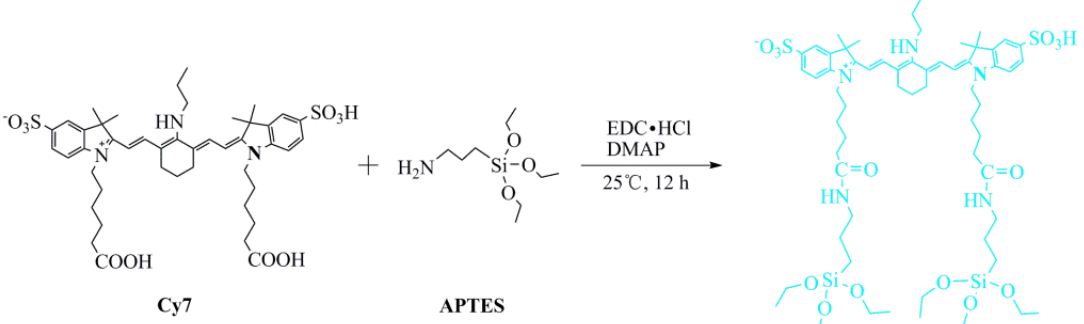

${ }^{1} \mathrm{O}_{2}$ self-monitoring unit (Cy7-APTES)

Scheme S1 Synthesis of PpIX-APTES, 2-pyridone-CPTES and Cy7-APTES derivatives. 
Synthesis of PpIX-APTES derivative: The synthesis routes of ${ }^{1} \mathrm{O}_{2}$ generating unit (PpIX-APTES derivative) are shown in Scheme S1. PpIX-APTES derivative was coupled to an alkoxysilane moiety (APTES) via EDC $\cdot \mathrm{HCl}$ (1-Ethyl-3-(3-dimethylaminopropyl)carbodiimide hydrochloride) and DMAP (4-dimethylaminopyridine). $0.01 \mathrm{mmol}$ of Protoporphyrin IX (PpIX) was dissolved in $5 \mathrm{~mL}$ of DMF. Then $0.10 \mathrm{mmol}$ of $\mathrm{EDC} \cdot \mathrm{HCl}$ and $0.08 \mathrm{mmol}$ of DMAP in $5 \mathrm{~mL}$ of DMF were added and the mixture was stirred under an atmosphere of $\mathrm{N}_{2}$ for $1 \mathrm{~h}$. Then, $0.20 \mathrm{mmol}$ of APTES was quickly injected into the mixture to activate coupling reaction and the mixture was continued to be stirred at room temperature for $12 \mathrm{~h}$. The product was precipitated with $10 \mathrm{~mL}$ of diethyl ether. The product was collected by filtration.

Synthesis of 2-pyridone-CPTES derivative: The synthesis routes of ${ }^{1} \mathrm{O}_{2}$ storage/ release unit (2-pyridone-CPTES derivative) are shown in Scheme S1. $0.5 \mathrm{mmol}$ of 2-pyridone, $0.60 \mathrm{mmol}$ of CPTES and $0.50 \mathrm{mmol}$ of $\mathrm{K}_{2} \mathrm{CO}_{3}$ were dissolved in $5 \mathrm{~mL}$ of absolute acetone. Then the mixture was heated to $50{ }^{\circ} \mathrm{C}$ and stirred under an atmosphere of $\mathrm{N}_{2}$ for $12 \mathrm{~h}$. The product was precipitated with $10 \mathrm{~mL}$ of diethyl ether. The product was filtered to remove $\mathrm{K}_{2} \mathrm{CO}_{3}$. Subsequently, the product was rotary evaporated to obtain pale-yellow oily liquid 2-pyridone-CPTES.

Synthesis of Cy7-APTES derivative: The synthesis routes of ${ }^{1} \mathrm{O}_{2}$ self-monitoring unit (Cy7-APTES derivative) are shown in Scheme S1. Cy7-APTES derivative was synthesized according to our reported work. ${ }^{1}$ In briefly, $\mathbf{C y} 7(0.01 \mathrm{mmol}), \mathrm{EDC} \cdot \mathrm{HCl}$ (0.1 mmol) and DMAP (0.08 mmol) were stirred in anhydrous DMF (5 mL) under 
nitrogen atmosphere at room temperature for $1 \mathrm{~h}$. Then $0.20 \mathrm{mmol}$ of APTES was quickly injected into the mixture to activate coupling reaction and the mixture was continued to be stirred at room temperature for $12 \mathrm{~h}$. The product was precipitated with $10 \mathrm{~mL}$ of diethyl ether. The product was collected by filtration.

Because the alkoxysilane moiety was severely sensitive to moisture and easy to hydrolyze polymerization, all the products (PpIX-APTES, 2-pyridone-CPTES and Cy7-APTES) were used for further functional silica nanocarrier (FSNC) formation directly from the reaction pot. Fortunately, the hydrolyzed products of PpIX-APTES and 2-pyridone-CPTES were confirmed via fourier transform mass spectrometer (FTMS). PpIX-APTES: FTMS (ESI) $m / z$ : calc. for $\mathrm{C}_{40} \mathrm{H}_{51} \mathrm{~N}_{6} \mathrm{O}_{8} \mathrm{Si}_{2}{ }^{-}[\mathrm{M}-\mathrm{H}]=$ : 799.33, found: 799.24; 2-pyridone-CPTES: FTMS (ESI) $m / z$ : calc. for $\mathrm{C}_{8} \mathrm{H}_{12} \mathrm{NO}_{4} \mathrm{Si}-[\mathrm{M}-\mathrm{H}]$ : 214.05, found: 214.08. The FTMS spectras of PpIX-APTES and 2-pyridone-CPTES are given in part 3 of supporting information.
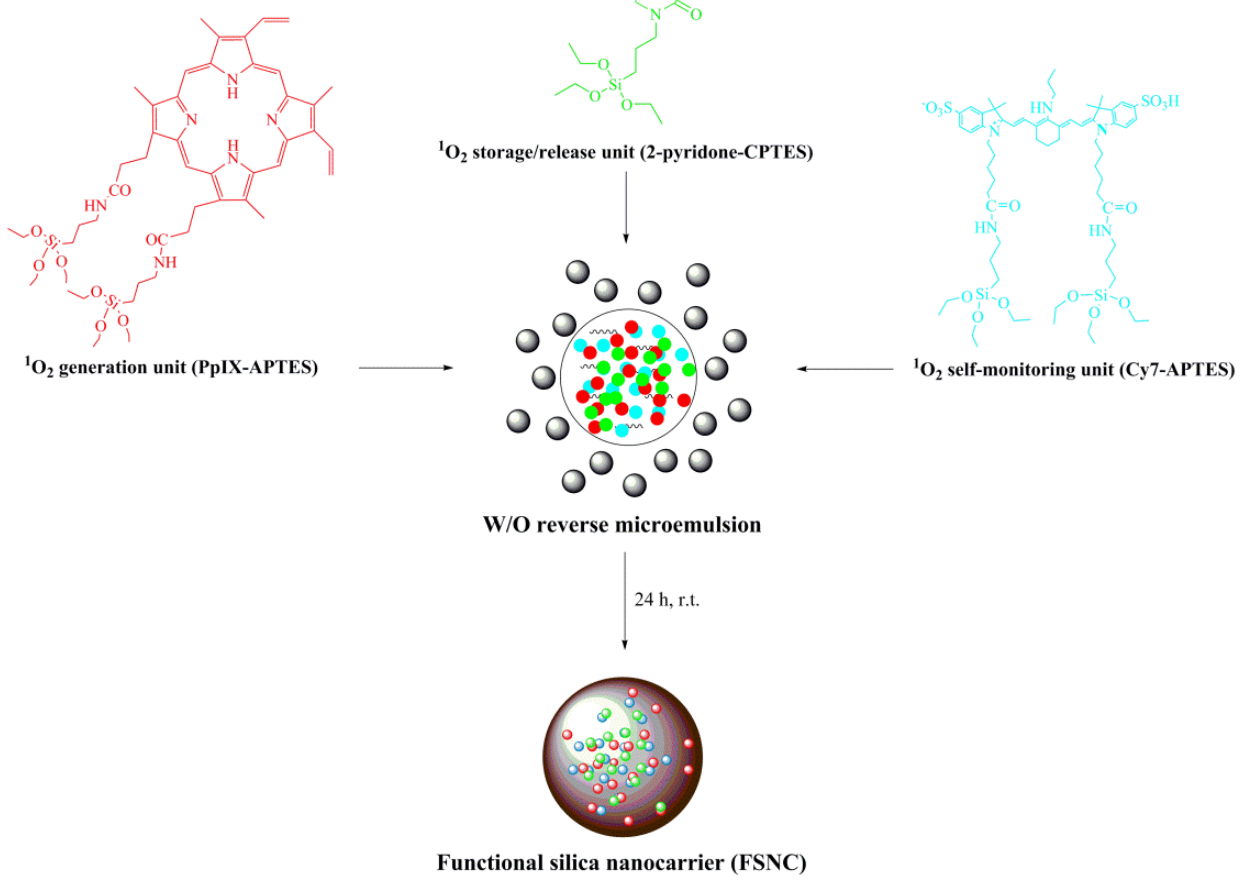

Scheme S2 Synthesis of functional silica nanocarrier (FSNC). 
Preparation of functional silica nanocarrier (FSNC): The preparation of FSNC was carried out by reverse microemulsion method. At room temperature, the reverse microemulsion system was prepared by mixing $3.5 \mathrm{~g}$ Triton $\mathrm{X}-100,4.4 \mathrm{~mL}$-octanol and $15 \mathrm{~mL}$ cyclohexan to stir for $30 \mathrm{~min}$. The prepared Cy7-APTES and 2-pyridone-CPTES were dissolved in $1 \mathrm{ml}$ of ultrapure water under ultrasound, and PpIX-APTES was dissolved in $5 \mathrm{ml}$ of cyclohexan. Then the mixture solutions were added dropwise into the reverse microemulsion system to continue stirring for $30 \mathrm{~min}$. Subsequently, $0.2 \mathrm{~mL}$ of TEOS was added at a rate of $0.02 \mathrm{~mL} / \mathrm{min}$. Finally, $0.1 \mathrm{~mL}$ of $\mathrm{NH}_{4} \mathrm{OH}(28-30 \%)$ was added at a rate of $0.02 \mathrm{~mL} / \mathrm{min}$ to initiate hydrolysis polymerization. After stirring the mixture for $24 \mathrm{~h}$, FSNC formation was terminated by acetone, and collected by centrifugation at 10,000 rpm. FSNC was washed with absolute ethanol for three times to remove unreacted free components, and then redispersed in ultrapure water. SiO $\mathbf{S i}_{2} \mathbf{P p I X \& C y 7}$ and $\mathrm{SiO}_{2} @ \mathbf{C y} 7$ as control nanoparticles were prepared using the same strategy. It should be noted that $\mathrm{SiO}_{2} @ \mathbf{P p I X \& C y 7 \text { did not contain 2-pyridone-CPTES, SiO }} @ \mathbf{C y} 7$ did not contain PpIX-APTES and 2-pyridone-CPTES.

Characterization: $\sim 45 \mathrm{~nm}$ diameter FSNC was observed via transmission electron microscope (TEM, see Figure 1a); FTIR measurements were performed on a FTIR spectrometer (see Figure S1).

\subsection{Steady-state absorption and fluorescence spectroscopy.}

The steady-state absorption spectroscopy was recorded in a quartz cuvette $(10 \times 10$ $\mathrm{mm}$ ) via a UV-Visible spectrometer named Cary 60 from Agilent Tech at room 
temperature. Working solutions of FSNC $\left(0.1 \mathrm{mg} \mathrm{mL}^{-1}\right)$, Free PpIX $(1 \mu \mathrm{M})$ and Cy7 $(1 \mu \mathrm{M})$ were prepared by diluting the stock solution in absolute ethanol.

The steady-state fluorescence spectroscopy was performed via a fluorometer named Cary Eclipse from Agilent Tech at room temperature. Working solutions of FSNC $\left(0.1 \mathrm{mg} \mathrm{mL}^{-1}\right)$, free PpIX $(1 \mu \mathrm{M})$ and Cy7 $(1 \mu \mathrm{M})$ were prepared under the same procedures as steady-state absorption test.

\subsection{Chemical stability}

At room temperature, the chemical stability of FSNC $\left(0.5 \mathrm{mg} \mathrm{mL}^{-1}\right)$ in phosphate buffer $(\mathrm{pH}=7.4,10 \mathrm{mM})$ and cell culture medium containing fetal bovine serum (FBS) over $14 \mathrm{~d}$ were tested through detecting fluorescence emission change of PpIX and Cy7 channel, respectively.

\section{6 ${ }^{1} \mathrm{O}_{2}$ release of $\mathrm{FSNC}, \mathrm{SiO}_{2} @ \mathrm{PpIX} \& \mathrm{Cy} 7$ and $\mathrm{SiO}_{2} @ \mathrm{Cy} 7$ in the presence and}

\section{absence of light}

Working solutions of FSNC, $\mathrm{SiO}_{2} @ \mathrm{PpIX} \& \mathrm{Cy} 7$ and $\mathrm{SiO}_{2} @ \mathrm{Cy} 7(0.5$ mg mL-1) were prepared in absolute ethanol, respectively. Before measuring fluorescence intensity $\left(\lambda_{\mathrm{ex}}=635 \mathrm{~nm}\right)$, the solutions were irradiated for $60 \mathrm{~s}$ by a red LED array $\left(\lambda_{\mathrm{ex}}\right.$ $=660 \mathrm{~nm}$ ) at optical density of $25 \mathrm{~mW} / \mathrm{cm}^{2}$. Subsequently, fluorescence intensity was measured again after the solutions were kept for 30 min under dark. This cycle was performed for 4 times.

\subsection{FSNC' releases stability of ${ }^{1} \mathrm{O}_{2}$}

After FSNC was stored in neutral PBS buffer for $14 \mathrm{~d}$, FSNC was washed three times with absolute ethanol and finally redispersed with $3 \mathrm{~mL}$ of absolute ethanol. 
Then, FSNC' releases stability of ${ }^{1} \mathrm{O}_{2}$ was performed under the same procedures as part 2.6.

\subsection{ROS levels detection in solutions.}

In singlet oxygen generation measurements, a commercial ROS probe 1,3-diphenylisobenzofuran (DPBF) was used. Before the measurement, FSNC, $\mathrm{SiO}_{2} @ \mathrm{PpIX} \& \mathrm{Cy} 7$ and $\mathrm{SiO}_{2} @ \mathrm{Cy} 7\left(0.1 \mathrm{mg} \mathrm{mL}^{-1}\right)$ were respectively dissolved in absolute ethanol, and then mixed DPBF at $50 \mu \mathrm{M}$. A red LED array (optical density of $25 \mathrm{~mW} / \mathrm{cm}^{2}, \lambda_{\text {ex }}=660 \mathrm{~nm}$ ) was used as excitated light source. The absorbance spectra of DPBF at $410 \mathrm{~nm}$ were recorded at different intervals (Light irradiation for $30 \mathrm{~s}$ and then dark for $30 \mathrm{~min}$, this cycle was performed for 4 times).

The relative singlet oxygen quantum yield $\left(\Phi_{\Delta}\right)$ of free PpIX and nanoparticles ( $\mathrm{SiO}_{2} @ \mathrm{PpIX}$ and $\mathrm{SiO}_{2} @ \mathrm{PpIX} \& 2$-pyridone) in ethanol were determined compared to methylene blue (MB). Free PpIX and nanoparticles (Optical densities were adjusted to the same value at $660 \mathrm{~nm}$ ) under irradiation (power density of $25 \mathrm{~mW} / \mathrm{cm}^{2}$ ) in the presence of DPBF $(50 \mu \mathrm{M})$ reduces their optical absorption, indicating formation of the singlet oxygen. It should be noted that the samples were irradiated for different times and then kept for 30 minutes under dark for the reaction to be complete before measuring the absorbance. $\Phi_{\Delta}$ values were calculated by the following equation:

$$
\Phi \Delta=\Phi_{M B} \times\left(\frac{k_{P \mathrm{pIX} \text { or nanoparticles }}}{k_{M B}}\right)\left(\frac{F_{M B}}{F_{\text {P } \mathrm{pIX} \text { or nanoparticles }}}\right)
$$

where $k$ is the bleach rate of DPBF absorbance $(410 \mathrm{~nm})$ with irradiation time, and $F$ is the absorption correction factor $\left(F=1-10^{-\mathrm{OD}}\right.$, OD value represents the absorption value of free PpIX or nanoparticles at $660 \mathrm{~nm}$, which were adjusted to the same 
value), given that $\Phi_{M B}=0.52$ in ethanol as reference. ${ }^{2}$

\subsection{HeLa cells culture}

HeLa cells were cultured in Dulbecco's Modified Eagle Medium (DMEM; GIBCO) containing $10 \%$ fetal bovine serum (FBS; GIBCO) and $1 \%$ antibiotics $\left(80 \mathrm{U} \mathrm{mL}^{-1}\right.$ penicillin and $0.08 \mathrm{mg} \mathrm{mL}^{-1}$ streptomycin; GIBCO). All the biochemical reagents described in this work were purchased from Nanjing Key GEN Bio TECH of China. Cultured cells were incubated at $37{ }^{\circ} \mathrm{C}$ in an atmosphere of $5 \% \mathrm{CO}_{2}$ in air.

\subsection{Cellular uptake of FSNC}

HeLa cells were seeded in a glass bottom dish (MatTek, $35 \mathrm{~mm}$ dish with a $20 \mathrm{~mm}$ bottom well) with an amount a density of $1 \times 10^{5}$ cells per dish. After the HeLa cells were cultured for $24 \mathrm{~h}$, cells were co-cultivated with FSNC $(2 \mu \mathrm{g} \mathrm{mL}-1)$ at $37{ }^{\circ} \mathrm{C}$ and $4{ }^{\circ} \mathrm{C}$ for $4 \mathrm{~h}$, respectively. Afterwards, the cells were washed three times with PBS $(\mathrm{pH}=7.4)$. For PpIX component of FSNC (orange channel), a standard 405-nm laser was used and image detection range was from $610 \mathrm{~nm}$ to $630 \mathrm{~nm}$. For Cy7 component of FSNC (red channel), a standard 635-nm laser was used and image detection range was from $655 \mathrm{~nm}$ to $755 \mathrm{~nm}$.

\subsection{Detection of intracellular ROS}

Intracellular ROS generation of FSNC was examined by using ROS probe 2',7'-dichlorofluorescin diacetate (DCFH-DA) and recorded by CLSM. The HeLa cells were seeded under the same procedures as part 2.10. After the HeLa cells were cultured for $24 \mathrm{~h}$, the medium was replaced with fresh medium, followed by addition of FSNC $\left(2 \mu \mathrm{g} \mathrm{mL}^{-1}\right)$ to continue incubating for $4 \mathrm{~h}$. Then, the cells were washed 
three times with PBS. Then the HeLa cells were stained with ROS probe (DCFH-DA) at the final concentration of $10 \mu \mathrm{M}$ and consecutively irradiated with a red LED array $\left(\lambda_{\mathrm{ex}}=660 \mathrm{~nm}, 25 \mathrm{~mW} / \mathrm{cm}^{2}\right)$ for $30 \mathrm{~s}$. After keeping under dark for $30 \mathrm{~min}$, the cells were washed three times with PBS. Then, a standard 488-nm laser was used and image detection range was from $510 \mathrm{~nm}$ to $540 \mathrm{~nm}$.

\subsection{Morphology change studies of HeLa cells after fractional PDT}

After PDT process, morphology change studies of the HeLa cells treated by FSNC were investigated by CLSM via Propidium Iodide (PI) single staining method. The HeLa cells were seeded under the same procedures as part 2.10. After the HeLa cells were cultured for $24 \mathrm{~h}$, the medium was replaced with fresh medium, followed by separately staining with FSNC, $\mathrm{SiO}_{2} @ \mathrm{PpIX} \& \mathrm{Cy} 7$ and $\mathrm{SiO}_{2} @ \mathrm{Cy} 7\left(2 \mu \mathrm{g} \mathrm{mL}^{-1}\right)$ to continue incubating for $4 \mathrm{~h}$. Afterwards, the cells were washed three times with PBS and then stained with $10 \mu \mathrm{M}$ of PI for $45 \mathrm{~min}$. Subsequently, the cells were washed three times and then $2 \mathrm{ml}$ of fresh medium was added. Then the cells were consecutively irradiated with a red LED array $\left(\lambda_{\mathrm{ex}}=660 \mathrm{~nm}, 25 \mathrm{~mW} / \mathrm{cm}^{2}\right)$ for $2 \mathrm{~min}$ and then kept under dark for $30 \mathrm{~min}$ before CLSM imaging.

\subsection{Cytotoxicity studies of FSNC}

The dark cytotoxicity and phototoxicity of FSNC were evaluated by 3-(4,5-dimethylthiazol-2-yl)-2,5-diphenyltetrazolium bromide (MTT) assays. HeLa cells harvested in a logarithmic growth phase were seeded in 96 -well plates $\left(1 \times 10^{4}\right.$ cells/well) and incubated for $24 \mathrm{~h}$. Then different concentrations of FSNC and PpIX were added into each well and incubated for $12 \mathrm{~h}$. After the removal of samples, fresh 
medium was added and then irradiated by the red LED array at a power density of 25 $\mathrm{mW} / \mathrm{cm}^{2}\left(\lambda_{\mathrm{ex}}=660 \mathrm{~nm}\right)$ for $2 \mathrm{~min}$ and then kept under dark for $30 \mathrm{~min}$. An ice box was disposed below the 96-well plates to eliminate the influence of temperature. MTT assays were immediately tested after PDT process without further incubation. Taking the same cell culture and staining methods under the premise, the dark cytotoxicity was measured without irradiation at the same time as control. The cells were then subjected to MTT assays with Microplate reader named Multiskan FC from Thermo scientific (Filter: $490 \mathrm{~nm}$ ).

\subsection{Annexin V-FITC/PI staining assay.}

HeLa cells were plated in 6-well culture plates and cultured for $24 \mathrm{~h}$ at $37^{\circ} \mathrm{C}$ in an atmosphere of $5 \% \mathrm{CO}_{2}$ in air. Then FSNC or $\mathrm{SiO}_{2} @ \mathrm{PpIX} \& \mathrm{Cy} 7$ was added at final concentrations of $4 \mu \mathrm{g} \mathrm{mL} \mathrm{m}^{-1}$. HeLa Cells without FSNC and $\mathrm{SiO}_{2} @ \mathrm{PpIX} \& \mathrm{Cy} 7$ were used as control. The plates were further incubated for $4 \mathrm{~h}$, and then the samples were washed three times with PBS. Fresh medium was added in the plates and then irradiated by the red LED array at a power density of $25 \mathrm{~mW} / \mathrm{cm}^{2}\left(\lambda_{\mathrm{ex}}=660 \mathrm{~nm}\right)$ for $2 \mathrm{~min}$ and then kept under dark for $30 \mathrm{~min}$. An ice box was disposed below the 6-well culture plates to eliminate the influence of temperature. The cells were digested with trypsin and suspended with binding buffer $(500 \mu \mathrm{L}$, KeyGEN BioTECH, Nanjing,

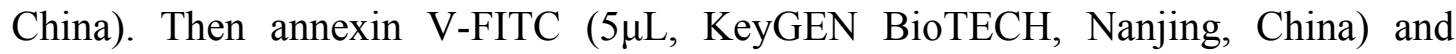
propidium iodide $(5 \mu \mathrm{L}$, KeyGEN BioTECH, Nanjing, China) were added and further incubated for $15 \mathrm{~min}$ in the dark at room temperature. HeLa cells were immediately analyzed on BD FACSCanto flow cytometer using 488-nm excitation, a 515-545 nm 
band pass filter for FITC detection and a filter $665-685 \mathrm{~nm}$ for PI detection. All measurements were performed in triplicate, and at least three independent experiments were carried out. 


\section{Supplemental spectra}

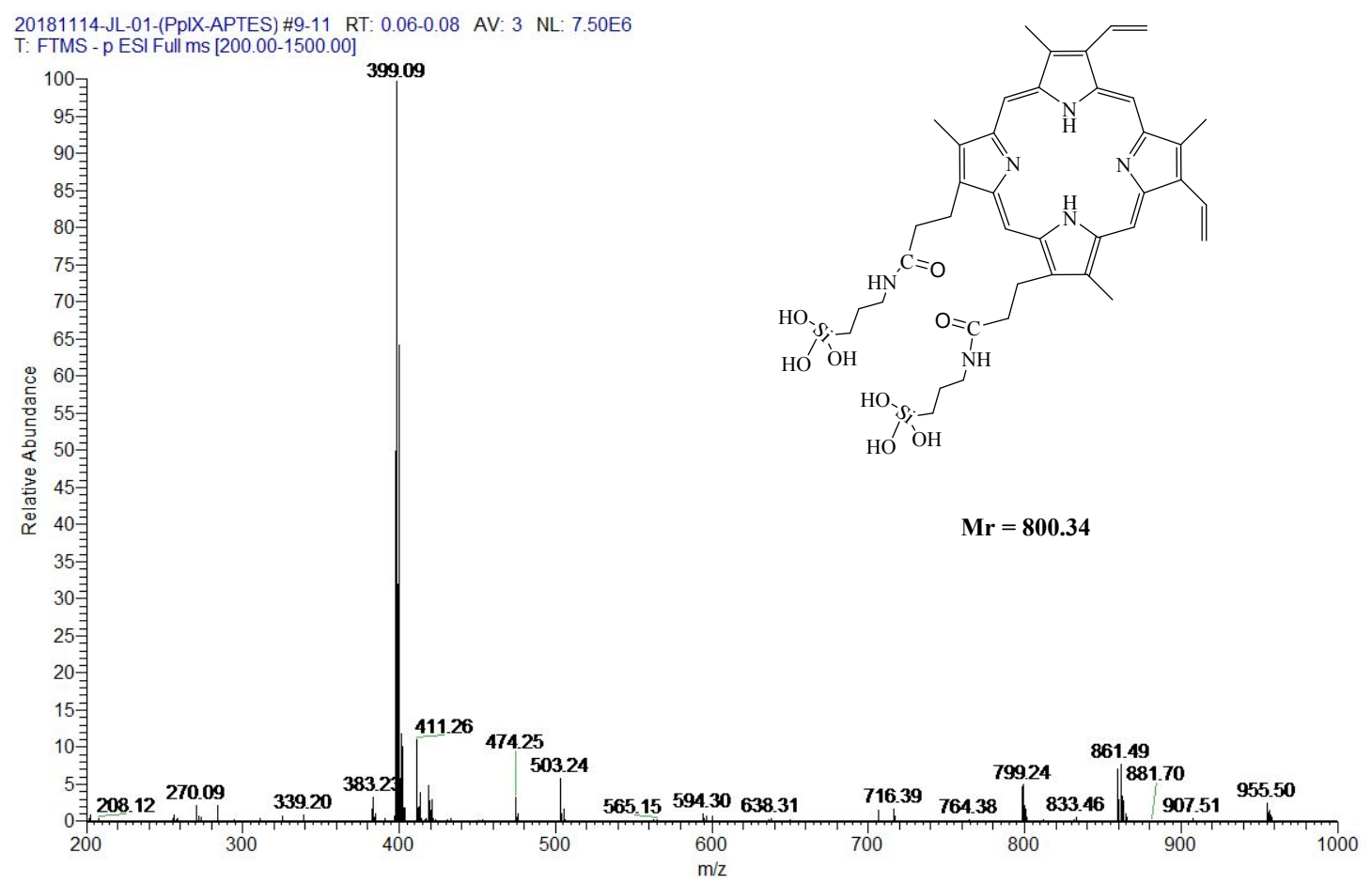

Figure S10. FTMS (ESI-) of PpIX-APTES.

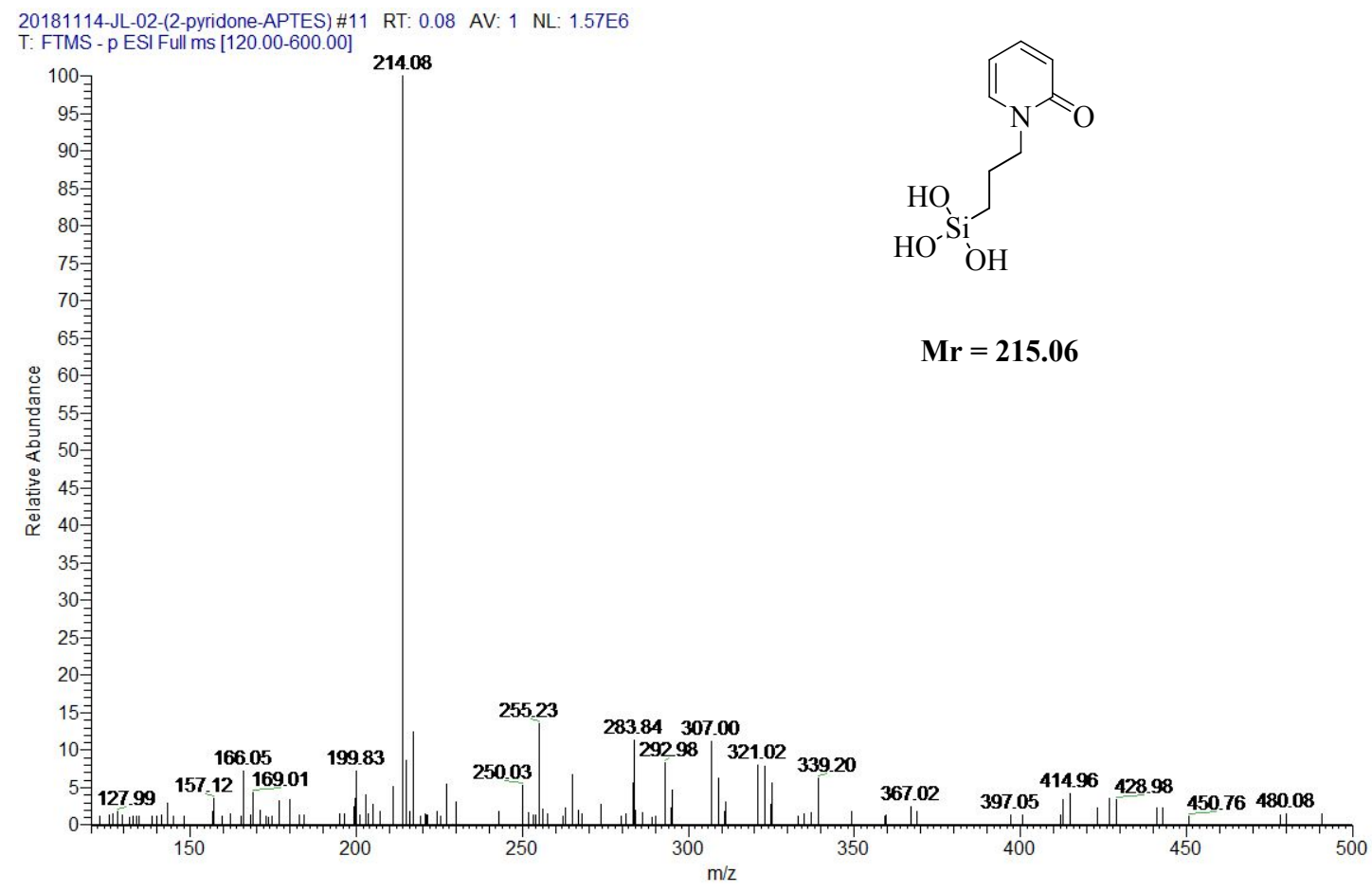

Figure S11. FTMS (ESI-) of 2-pydidone-CPTES. 


\section{References}

(1) Jiao, L.; Song, F.; Zhang, B.; Ning, H.; Cui, J.; Peng, X. Improving the Brightness and Photostability of NIR Fluorescent Silica Nanoparticles through Rational Fine-Tuning of the Covalent Encapsulation Methods. J. Mater. Chem. B 2017, 5, $5278-5283$.

(2) Bonacin, JA.; Engelmann, FM.; Severino, D.; Toma, HE.; Baptista, MS. Singlet Oxygen Quantum Yields $\left(\Phi_{\Delta}\right)$ in Water Using Beetroot Extract and an Array of Leds. J. Brazil. Chem. SOC 2009, 20, 31-36. 